\title{
Programa de zoneamento, monitoramento e pesquisas nos sítios pré - históricos do Litoral Central do Rio Grande do Sul.
}

\section{Sobre Histórias e Memórias do Litoral Central: uma proposta de construção patrimonial sobre os sítios arqueológicos da região da Restinga da Lagoa dos Patos.}

LEPAN - FURG

\author{
Vanderlise Machado Barão \\ Eduarda Lopes Machado \\ Denise Marques Ferreira ${ }^{3}$
}

Resumo: A memória coletiva de um povo é preservada no repasse de seus costumes, pensamento, escritos e construções. Quando há um consentimento entre a maioria da população herdeira dessas memórias de que é importante que esse passado permaneça vivo, chama-se isso de patrimônio. Dessa forma pode denominar-se patrimônio os bens culturais materiais e/ou imateriais de um povo, podendo estar ele extinto ou vivo. Este conceito de cuidado com a memória de um grupo, não é restrita a sociedade ocidental, existe desde o mundo clássico a sociedades tribais. A importância, assim, do pensamento de patrimônio em uma sociedade é de suma relevância, pois trata-se de uma parte constituinte da identidade sociocultural dos indivíduos.

O Litoral Central do Rio Grande do Sul abriga uma grande quantidade de vestígios de um passado indígena de intensa integração com o meio ambiente referente ao bioma da restinga da Lagoa dos Patos. Esses registros arqueológicos encontram-se espalhados em toda a região costeira, porém nosso estudo foca-se no território de três municípios que estão passando por processos de expansão urbana e industrial, e que em consequência disso o risco de desaparecimento desses registros é cada vez mais eminente.

Os municípios são Mostardas, Tavares e São José do Norte, neles encontramos vestígios cerâmicos e líticos sob dunas, caracterizando o que

${ }^{1}$ Arqueóloga, coordenadora do Laboratório de Ensino e Pesquisa em Arqueologia e Antropologia LEPAN/FURG, email: vandermbya@gmail.com

${ }^{2}$ Graduanda do curso de Bacharelado em Arqueologia - FURG, bolsista LEPAN/FURG, email: dudalopesm@gmail.com

${ }^{3}$ Graduanda do curso de Bacharelado em Arqueologia - FURG, bolsista LEPAN/FURG, email: de.biul@hotmail.com 
chamamos de sítios dunares, os famosos cerritos e sambaquis. Estes últimos merecem uma atenção grande, pois por se encontrarem próximos a áreas de balneários vem sendo depredados em função de atividades de lazer e esportes realizados com jipes que aproveitam o formato desses sítios para desenvolverem suas performances. Em decorrência disso alguns sambaquis foram completamente achatados, e seu material encontra-se espalhado em grandes manchas de conchas.

A população residente nesses municípios é bastante diversificada, tendo desde os grandes proprietários de terra, que possuem em suas propriedades registros arqueológicos, pequenos agricultores, pescadores, quilombolas e outros membros da sociedade que exercem atividades diversas. Muitas dessas pessoas têm conhecimento sobre a existência desse patrimônio arqueológico, porém não sabe exatamente qual o valor desses registros.

A proposta deste projeto visa dialogar com essas diferentes esferas da sociedade que habita a região do Litoral Central, construindo com eles uma dinâmica de preservação desses sítios, bem como a apropriação desses lugares como lugares de memória, trazendo a herança indígena da região para mais perto da comunidade, numa construção positiva da imagem do índio. Da mesma forma, pensamos em elaborar programas que envolvam o desenvolvimento turístico do lugar incluindo os sítios arqueológicos nesses roteiros, como forma de incorporar esses registros e documentos da história da região costeira ao planejamento local de desenvolvimento, fazendo assim com que esses lugares passem a ser preservados e cuidados pelo poder público e pela sociedade do entorno.

Palavras chave: Memória, patrimônio, arqueologia colaborativa

\begin{abstract}
The collective memory of people is preserved when the costumes, knowledge, writing and buildings are transferred between them. When the heir people have knowledge of the importance of these memories to still alive, this is call patrimony. Thus might be called patrimony the material or immaterial culture of people, it may be extinct or alive. This concept must be careful with the memory of a group, is not restricted to western society, it is from the classical world to tribal societies. The importance of thinking of heritage in a society is of great importance, because it is a constituent part of the socio-cultural identity of individuals.
\end{abstract}

The Central Coast of Rio Grande do Sul is home to a lot of traces of an indigenous past of intense integration with the environment in this biome the sandbanks of the Patos Lagoon. These archaeological remains are scattered throughout the coastal region, but our study focuses on the territory of three 
municipalities which are urban expansion and industrial processes, and that in consequence the risk of disappearance of these remains is becoming increasingly prominent.

The municipalities are: Mostardas, Tavares and São José do Norte, in them we find ceramic and lithic remains under dunes, featuring what we call the dune sites, they are known as Cerritos and Sambaquis. These latter deserve great attention, because they are near areas of spas has been vandalized in leisure activities and sports performed with jeeps that take advantage of the format of these sites to develop their performances. As a consequence some sambaquis were completely flattened, and his material is spread on large patches of shells.

The resident population in these municipalities is very diversified, where we have the large landowners, they have in their properties, archaeological remains, small farmers, fishermen, quilombolas and other members of society with various activities. Many of these people have known about the existence of archaeological patrimony, but do not know exactly which one the value of the remains.

The proposal of this project is to dialogue with the different spheres of society that lives on the Central Coast region, building with them a dynamic preservation of these sites, as well as the appropriation of these places as places of memory, bringing in the indigenous bequest of the region closer to the community in a positive construction of the image of the Indian. In the same manner, we think of develop programs that involve the development of tourism of the place including the archaeological sites in these scripts, as a way of incorporate these records and documents the history of the coastal region to the local development planning, thus making these places are now preserved and maintained by the government and by this around population.

Keywords: Memory, patrimony, collaborative archeology

ABSTRAIT: La mémoire collective d'un peuple est préservée dans le transfert de leurs coutumes, les pensées, les écrits et les bâtiments(constructions). Lorsqu'il y a consentement parmi la majorité de la population de ces souvenirs que elle hérite, est important que ce passé reste vivant, est denominé comme patrimoine. De toute façon vous pouvez appeler aussi du patrimoine culturel matériel / immatériel d'un peuple, qui peut être il éteint ou vivant.

Ce concept de soins avec le souvenir d'un groupe, ne se limite pas qu'à la société occidentale, existe depuis le monde classique des sociétés tribales.

\begin{tabular}{|l|l|l|l|l|l|l|}
\hline (C Rev. Arqueologia Pública & Campinas, SP & v.9 & No.(11) & p.12-29 & suplemento & ISSN 2237-8294 \\
\hline
\end{tabular}


La pensée du patrimoine dans une société est donc la plus importante, car c'est un élément constitutif de l'identité culturelle des individus.

Le litoral centrale du Rio Grande du Sud abrite un grand nombre de traces du passé autochtone d'intense intégration avec l'environnement pour la biome de "Restinga de Lagoa dos Patos". Ces documents archéologiques sont éparpillées dans la région litorale, mais notre étude se concentre sur le territoire des trois communes qui sont en processus d'expansion urbaine et industrielle,et qu'en conséquence le risque de disparition de ces enregistrements est plus en plus imminent. Les municipalités sont Mostarda, Tavares et São José do Norte, en eux, nous avons trouvé des vestiges en céramique et lithique que nous avons trouvé sous les dunes, ce que nous appelons "sitios dunares", la célèbre cerritos et sambaquis. Ce dernier mérite beaucoup d'attention parce qu'ils sont proches de zones de "balneirado" qui a été "depredado" en fonction du loisir et activités sportifs menées avec les jeeps qui tirent profit du format de ces lieux pour développer leurs performances. Ainsi certains "Sambaquis" ont été complètement rasés, et leur matériel se trouve( s'etend) comme grandes manches de coques. La population résidente dans ces municipalités est assez diversifiée, depuis les grands propriétaires terriens, qui sont propriétaires de leurs propriétés dans les données archéologiques, petits agriculteurs, pêcheurs, quilombo et autres membres de la société engagée dans diverses activités. Beaucoup de ces gens connaissent l'existence de ce patrimoine archéologique, mais ne savent pas exactement quelle est la valeur de ces enregistrements. L'objectif de ce projet a pour but de s'engager avec ces différentes sphères de la société qui vit dans la région de la litoral centrale, à construire une dynamique de préservation de ces sites, ainsi que l'appropriation de ces lieux comme des lieux de mémoriques, mettant l'héritage indiegene de cette région et la rapprocher de la Communauté, dans une construction positive de l'image du peuple indigene. De même, nous pensons développer des programmes qui impliquent le développement touristique de l'endroit, y compris les sites archéologiques dans ces scripts comme un moyen d'incorporer ces dossiers et les documents l'historique de la région litorale, la planification du développement local, ces places, seront préservés et pris en charge par le gouvernement et la société environnante.

Mots-clés : mémoire, patrimoine, archéologie collaborative

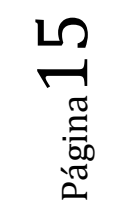

\begin{tabular}{|l|l|l|l|l|l|l}
\hline (C) Rev. Arqueologia Pública & Campinas, SP & v.9 & No.(11) & p.12-29 & suplemento & ISSN 2237-8294
\end{tabular} 
O presente programa que vem sendo desenvolvido na região do Litoral Central do Rio Grande do Sul foi elaborado a fim de atender demandas a respeito da formação de memória e identidade regional, bem como dar suporte para a construção de um diálogo entre patrimônio arqueológico, meio ambiente, cultura, educação e comunidade local, já que o principal objetivo dessa proposta seria a construção do conhecimento a respeito das populações pretéritas da região da restinga da Lagoa dos Patos.

A proposta visa ampliar os conhecimentos a respeito do patrimônio arqueológico naquela região, bem como dar continuidade a um trabalho já iniciado pela equipe do LEPAN / FURG, que no passado possuía um projeto de registro e pesquisa em sítios arqueológicos no litoral central do Rio Grande do Sul. Essas pesquisas foram coordenadas pelo Prof. Dr. Pedro Mentz Ribeiro, no final da década de 1990, apresentando uma proposta de prospecções arqueológicas e coletas de amostras nos sítios da região, e mostrando à comunidade a existência de vários vestígios arqueológicos, tanto de uma história ameríndia, como histórico- colonial, chamando a atenção para a necessidade de preservação desses vestígios e lugares, como Lugares de Memória para os atuais moradores das cidades litorâneas. Propomos aqui neste ensaio apresentar as ações previstas nesses trabalhos de conscientização e educação para o patrimônio nas cidades de São José do Norte, Tavares e Mostardas onde atualmente o LEPAN desenvolve pesquisa piloto em alguns sítios arqueológicos pré-coloniais da região, buscando empregar equipamentos tecnológicos não intrusivos para avaliação do potencial arqueológico desses lugares. Na medida em que temos um estudo dos estratos arqueológicos e das incidências de vestígios do passado da região pode-se construir um banco de dados, plotando todos os sítios com suas referências e características e dessa forma poder orientar o poder público e os moradores para a preservação do patrimônio, bem como proceder a uma escavação arqueológica em alguns sítios de relevância para as pesquisas na região e consequentemente atingir a comunidade em sua construção histórica e identitária, bem como da cultura local.

Dessa forma acreditamos que a educação patrimonial, associada às pesquisas e ao zonemento das áreas de potencial arqueológico da região da restinga da Lagoa dos Patos pode se tornar um elemento de vital importância para o bom desenvolvimento científico e ampliar o conhecimento a respeito das populações pretéritas que habitaram e manejaram a região do Litoral Central. As comunidades contatadas nos três municípios que compõem a região mostraram-se muito solicitas e interessadas com a sua história, vindo mesmo trazer informações a respeito de possíveis vestígios arqueológicos à equipe que se encontrava em campo, porém, 
como esses sítios se encontram dentro de propriedades privadas, acontece de eles serem gradativamente deteriorados em função das lidas no campo, como agricultura e pecuária.

É necessária neste tipo de trabalho a colaboração da comunidade e também a compreensão do trabalho arqueológico para que não haja um distanciamento brusco entre pesquisas e conhecimentos locais, já que a história é construída por estas memórias e estes saberes, tanto quanto pelos documentos escritos e materiais deixados ao longo do tempo. Portanto, objetivamos trazer ao grande público (comunidade local, regional, estadual e nacional) os resultados das pesquisas científicas realizadas pela equipe que se formará em seu núcleo, assim como dar suporte para os professores e demais interessados da região trabalharem com a temática da memória e patrimônio, tanto em sala da aula, como em demais atividades turísticas que venham a ser implementadas.

\section{O Plano de Educação Patrimonial no litoral central.}

O Plano de Educação Patrimonial para o Litoral Central - RS é composto de três etapas interligadas de ações educativas e de divulgação do conhecimento produzido pelas pesquisas acadêmicas que serão desenvolvidas em seu curso:

1. O Núcleo de Criação e Apoio à Escola, onde serão desenvolvidas as atividades de criação e montagem de material didático - pedagógico, sobre a temática: patrimônio e memória. Neste núcleo serão elaborados cursos de capacitação para professores da região, que serão direcionados e disponibilizados junto à Secretaria de Educação dos municípios, visando atender as escolas de base (ensino fundamental e médio), da região do Litoral Central no intuito de expandir o conhecimento sobre a temática em questão, dando maiores subsídios pedagógicos para os professores de história que já atuam na rede municipal. Aqui, os interessados (comunidade local, visitantes, alunos de escolas, pesquisadores, etc.) encontrarão subsídios para compreenderem e repensarem o patrimônio material e imaterial, através de exposições, vídeos, livretos, etc., informações sobre o passado (arqueologia, história e ambiente) e presente (ecologia, sobreposições de sociedades na paisagem local, etc) na região litorânea do Rio Grande do Sul; 
2. Oficinas Públicas, onde serão realizadas oficinas de fotografia, seminários temáticos, visitas guiadas e trilhas arqueológicas, abertas a comunidade. Está prevista a montagem de uma exposição itinerante que será realizada a partir das fotos e informações produzidas nas oficinas, utilizando o material produzido pela comunidade participante. Esta exposição deverá circular entre lugares públicos dentro e fora do município visando expandir ao conhecimento público os elementos que compõem a história da localidade.

3. O Seminário Temático: que deverá se constituir de um evento proposto à comunidade em geral, onde pesquisadores e educadores acadêmicos poderão dialogar junto aos indivíduos da comunidade, que da mesma forma são formadores de opinião. Este evento deverá se realizar na Comunidade, nas dependências de uma das escolas ou num centro comunitário, e nele serão ouvidas histórias locais e memórias, conjuntamente com produção cientifico acadêmicas, sendo então criado um diálogo entre estas duas instâncias da construção histórica e das identidades regionais. Esse evento também possui o intento de criar vínculos entre academia e comunidade, levando até a localidade pesquisada os elementos produzidos pelas pesquisas universitárias, dessa forma aproximando a universidade das pessoas.

\section{O Ambiente Físico e Cultural do Litoral Central do Rio Grande do Sul.}

A importância de se fazer pesquisa e um zoneamento dos sítios arqueológicos préhistóricos na região compreendida pelo Litoral Central se faz necessário devido à abrangência e interesse advindo das populações locais sobre seu patrimônio histórico e cultural, bem como por sua importância ecológica e arqueológica, já que a região comporta diferentes nichos e paisagens que se interligam e fazem parte do cotidiano e da economia das populações que hoje as habitam, assim como o fizeram para as populações do passado. Dessa forma vários pesquisadores já se debruçaram sobre pesquisas arqueológicas e etnográficas nesta região, porém seus resultados acabam ficando distantes das comunidades locais, já que o material e o conhecimento produzido estão abrigados em instituições de pesquisa e universidades, distantes do local pesquisado. Assim, o LEPAN / FURG, cumprindo o seu papel de entidade educacional e de desenvolvimento local propõe projetos de pesquisa e extensão mais próxima das comunidades locais. Estes projetos serão postos em prática nos municípios de São José do Norte, Tavares e Mostardas em 
função do interesse da Universidade em desenvolver pesquisas mais aprofundadas na zona costeira e principalemnte na região do estuário da Lagoa das Patos que apresenta um grande potencial arqueológico já apontado em pesquisas anteriores, onde a equipe do LEPAN/FURG, juntamente com professores/pesquisadores da Escola de Engenharia - FURG, estão aplicando técnicas de monitoramento e pesquisa em sítios arqueológicos dunares fazendo uso de equipamentos de geofísica para avaliação do potencial arqueológico e das interferências naturais do meio físico sobre os vestígios antrópicos em sítios conhecidos da região.

\section{Propostas de desenvolvimento de pesquisas e monitoramento do patrimônio ARQUEOLÓGICO}

A região costeira é um dos territórios mais povoados do país, sendo que desde tempos imemoriais as zonas litorâneas exerceram uma forte atração as populações humanas bem como de outras espécies animais, tornando-se nichos de biodiversidade bastante importantes para o planeta. Essa atração, embora tenha sido o motivo pelo qual as zonas costeiras abrigam essa biodiversidade, tem também causado muitos danos ao próprio sistema costeiro, principalmente porque alí formou-se uma gama de cidades e municípios que vem crescendo economicamente nos últimos anos e ampliando muito suas atividades extrativistas e industriais. Os avanços economicos são necessários para a melhoria de vida da população como um todo, porém há comunidades que vivem de forma tradicional ou que mantém economias de subsistência ainda nessas zonas e que vem sendo engolidas pelos projetos desenvolvimentistas. Essas populações, bem como seu patrimônio cultural merecem atenção, pois fazem parte de um arcabouço identitário e socio-econômico local que deve manter-se ou ser monitorado para integrar-se de forma positiva às novas perspectivas econômicas vigentes. Dessa forma torna-se necessário um mapeamento dessas culturas e do patrimônio a elas vinculados, bem como do patrimônio arqueológico que existem ainda nesses lugares e que se não forem estudados irão desaparecer diante das frentes de expansão da zona costeira.

Esse patrimônio arqueológico, principalmente o pré-histórico, não possui precedentes em outros lugares, sendo portanto, documentos únicos e já bastante fragmentados em função de que os lugares são sobrepostos por populações que renovam as paisagens constantemente. Há indicios de ocupações ameríndias na zona costeira que remetem há tempos bastante recuados na memória histórica, e esses indícios levam a crer que muito 
antes de as frentes progressistas de agora estarem aqui instalando suas máquinas e fábricas, populações indígenas já alteravam o meio ambiente com suas técnicas construtivas e sua tecnologia econômica, criando lugares que hoje compõem a paisagem da restinga da Lagoa dos Patos e do litoral marinho.

Buscando compreender essas transformações e construir conhecimento sobre essas populações e seu manejo ambiental nessas zonas costeiras é que propomos esse programa a fim de ampliarmos nosso conhecimento sobre esses sistemas tão complexos que formam a zona litorânea de nosso estado.

Assim, acreditamos que na formação do educador pesquisador é fundamental o desenvolvimento de atividades ligadas à busca das identidades das comunidades envolvidas no ato educativo. O conhecimento histórico é aqui pensado como uma via para a busca e afirmação de identidades, pois ele parte da realidade local, o contexto histórico da região.

Aproveitando a riqueza das manifestações histórico-culturais do litoral, este proposta apresenta-se como uma possibilidade para ampliar os estudos sobre memória e patrimônio nesta região, qualificando os discentes nas atividades de cunho histórico e arqueologico, bem como ampliando o diálogo entre academia e comunidades locais. Em outras palavras, trata-se de intensificar e complexificar as possibilidades de manejo patrimonial da região, pois como afirma Lucien Febvre (1996: 537)

A história se faz com documentos escritos, sem dúvida. Quando estes existem. Mas pode fazer-se, deve fazer-se sem documentos escritos, quando não existem. Com tudo que a habilidade do historiador Ihe permite utilizar para fabricar o seu mel, na falta das flores habituais. Logo, com palavras, signos, paisagens e telas. Com as formas dos campos e das ervas daninhas. Com os eclipses da lua e a atrelagem dos cavalos de tiro. Com os exames de pedras feitos pelos geólogos e com as análises feitas pelos químicos. Numa palavra, com tudo o que, pertencendo ao homem, depende do homem, serve o homem, exprime o homem, demonstra a presença, a atividade, os gostos e as maneiras de ser do homem.

A ação pedagógica se concentra, cada vez mais, em processos de socialização que incluem o professor como mais um sujeito do grupo que se reúne para aprender, colocando-o também como pesquisador, tanto do que lhe é desconhecido e junto com seus alunos, como 
pesquisador de sua própria prática. Isso é, alguém que realmente articula as reflexões teóricas aos processos educacionais.

Este programa representa a possibilidade para implementar, no âmbito de um projeto de arqueologia, ações de ensino, pesquisa e extensão que consolide as políticas institucionais possibilitando que os pesquisadores envolvidos tenham uma trajetória profissional alicerçada na investigação, interrogação e proposição de alternativas para a educação como um todo. Assim, as práticas implementadas são direcionadas para a discussão, reflexão, sistematização e socialização dos estudos e pesquisas realizados. As ações desse programa têm como foco as demandas das comunidades de São José do Norte, Tavares e Mostardas, e também a acadêmica provocando a ressignificação das práticas arqueológicas e dos olhares para o conhecimento produzido.

\subsection{Pesquisa Arqueológica}

A pesquisa arqueológica propriamente dita deverá ocorrer em alguns sítios selecionados a partir do zoneamento e mapeamento dos sítios registrados pela equipe de pesquisadores juntamente com as demandas das comunidades e do poder público dos municípios envolvidos, já que há indicações de interesses de exploração turistica de algumas áreas que mantém em seu cerne sítios arqueológicos e áreas com alto potencial arqueológico.

Os sítios dunares, que já vem sendo analisados no município de São José do Norte, requerem um estudo minucioso de seu comportamento natural para que se possa avaliar a melhor metodologia para a realização de uma intervenção arqueológica. Há necessidade de se fazer algumas intervenções nesse tipo de sítio por dois motivos: o primeiro deles é a falta de conhecimentos a respeito da ocupação humana que deixou esses vestígios no ambiente, e o segundo seria o risco de perda desse documento em função da expansão urbana do município e dos empreendimentos que vem avançando sobre essas zonas onde esses vestígios estão depositados. Como são vestígios cerâmicos e possíveis vestígios de acupação residencial ameríndia, que não deixou contruções em pedras ou tijolos, esses vestígios são altamente destruidos pela sua fragilidade e dessa forma perde-se uma grande parte da história da ocupação humana do território.

No município de Mostardas, a comunidade quilombola de Casca mostrou interesse em pesquisar os sambaquis que se encontram dentro de seu território, em função de 
desenvolverem ali atividades turísticas e desejarem ter maior conhecimento desses lugares para complementarem suas atividades educacionais durante as visitações.

Para a academia, a pesquisa nesses sítios tem também o caráter de orientação ás populações circunvizinhas para a preservação desses lugares e que isso somente é possível com a educação e orientação sobre o valor desses documentos de memória.

Para esse fim, o programa visa principalmente a colaboração entre pesquisadores e comunidades locais para o desenvolvimento dessas atividades e do monitoramento dos sítios arqueológicos que estão integrados à outras atividades econômicas e sociais dentro dos municípios abrangidos pelos projetos. Dessa forma atividades educativas e produção de materiais de divulgação e orientação para a preservação serão foco de nossas atividades na região.

\subsection{Exposições}

A exposição itinerante, fruto de pesquisas etnográficas e arqueológicas, bem como das oficinas realizadas junto as comunidades, vêm apresentar a possibilidade de integração universidade - comunidade local. Essas exposições deverão se apresentar em forma de pôsteres, facilitando seu manejo e transporte, já que se destinam em princípio à circulação nos lugares públicos da cidade, como escolas, centros comunitários, etc. O modelo itinerante dos painéis facilita a expansão do conhecimento para fora do meio acadêmico, já que abrange práticas pedagógicas e educativas junto à sociedade envolvente, que comumente não está dentro da academia acompanhando a construção desse conhecimento.

Numa proposta de educação patrimonial conjunta com a sociedade envolvente, temos a intenção de ampliar o conhecimento sobre a memória histórica e cultural dos povos do litoral, bem como apresentar os resultados das pesquisas realizadas na academia para o público em geral, principalmente aos estudantes da escola de base.

\subsection{Produção de material didático - pedagógico}

A parceria entre arqueologia, educação patrimonial e ambiental, e ensino de história é um caminho possível para a construção da cidadania. Ações pedagógicas envolvendo todas essas áreas do conhecimento para a construção de material lúdico e didático constituem possibilidades para a inclusão da arqueologia e do patrimônio no ensino fundamental e médio resignificando saberes e fazeres. 
Os pesquisadores têm sido desafiados constantemente pelas discussões acerca da construção do conhecimento. Isso exige uma constante renovação na escrita das disciplinas, de forma a contribuir para a produção de novos recursos para o ensino, sobretudo a elaboração de materiais pedagógicos, atingindo tanto o ambiente acadêmico quanto o escolar.

As atividades deste projeto têm como foco ampliar a discussão do ensino e da pesquisa oferecendo espaços de diálogo aos profissionais da educação, assim como criar vínculos da universidade com a escola e a comunidade na busca de um maior entendimento sobre o significado da categoria patrimônio (visando tanto o patrimônio cultural como o ambiental). São momentos de aproximação com a pesquisa e o ensino que ampliam a ligação entre Ensino Superior e Educação Básica buscando a construção de uma cidadania ampla.

Nesse bojo surge a proposta de criação de um curso de capacitação para os professores da rede pública, em parceria com as Secretarias de Educação Municipal, para a construção de diálogos e propostas que desenvolvam materiais didáticos para dar apoio a uma nova proposta de ensino nas escolas, voltada para o patrimônio local, mas envolvendo os saberes e a memória da própria comunidade, pois essa constrói e recria essa memória constantemente e os pesquisadores e educadores não podem se abster desses conhecimentos.

Pois como nos apresenta Mario Chagas (2003:97),

Ainda que algumas práticas vinculadas ao poder público alimentemse de uma concepção coisificada e restritiva, que considera 0 patrimônio cultural um conjunto de bens móveis e imóveis, nos últimos trinta anos os conceitos de valor histórico e artístico, de patrimônio e bem cultural, vêm sendo gradual e sistematicamente redefinidos e ampliados.

Dessa forma, a proposta do projeto é de se fazer ouvir pela comunidade e a partir daí lançar mão dos conhecimentos adquiridos pela pesquisa acadêmica e pela oralidade da comunidade escolar, produzindo um material que dialogue entre esses dois pólos, dando subsídios para o trabalho de professores e alunos no âmbito da formação escolar de base, ampliando os conhecimentos dos alunos e da comunidade sobre o seu espaço cultural e de memória histórica.

N 
Os materiais propostos a princípio, são a criação das exposições itinerantes, materiais lúdicos, um livro e catálogos informativos, mas a idéia é de ampliar a produção de acordo com a demanda da comunidade.

3.4. Formação de monitores sobre patrimônio cultural (arqueologia, história, etnologia e meio ambiente)

Formar pesquisadores e educadores nas áreas de história, arqueologia e antropologia se faz mister, porém qual história, qual arqueologia, qual antropologia? Devemos estar atentos para o poder exercido por estas disciplinas, já que elas são formadoras da opinião pública e da memória histórica de um povo. Quando falamos em um país multiétnico, não podemos esquecer que este país foi construído sobre outros territórios. Em vários momentos de sua formação vários povos interagiram e construíram histórias. Por isso a educação patrimonial é um assunto tão relevante nas localidades onde são desenvolvidas as pesquisas acadêmicas. É preciso formar não só pesquisadores e educadores, mas é preciso formar cidadãos. Estes que irão dar continuidade à preservação do legado patrimonial de sua comunidade, ajudando a construir uma identidade e uma história próprias, onde se preservarão não só objetos, mas memórias.

Dessa forma, a iniciativa dos pesquisadores do LEPAN/FURG, de formarem monitores nas comunidades locais dos municípios em questão, buscando pessoas da própria comunidade, educadores, alunos, pescadores, artesãos, etc., para que divulguem sua história e possam ajudar a instruir visitantes junto a esses legados patrimoniais que ali se encontram, é mais uma maneira de enraizar essas memórias e valorizar a história local. Assim, formam-se cidadãos - pesquisadores, e estes serão os responsáveis por "contar" a história aos visitantes e interessados.

Pensa-se formar esses monitores, para que durante as pesquisas arqueológicas, estes possam realizar os roteiros de visitação aos sítios, dando instruções a respeito da pesquisa e dos achados arqueológicos, bem como possam num futuro próximo, realizar roteiros turísticos com visitações a lugares de relevância histórica e patrimonial, conforme o interesse que tem demonstrado a comunidade num desenvolvimento turístico para incrementar a economia local. 
A proposta de se dar bases para a construção histórica do patrimônio local, com a produção e pesquisas acadêmicas e uma preocupação com a educação básica e produção de subsídios para trabalhar nas escolas e na comunidade, sobre temáticas vinculadas a etnicidade, história e arqueologia da região costeira, e principalmente da região do litoral central, é exatamente mexer nessas estruturas duras da construção histórica que ainda permanece dentro do senso comum e também nas academias. O cidadão que tiver acesso a outras "histórias" poderá estar mais preparado para enfrentar os desafios da globalização, onde a sala de aula não é mais suficiente para desenvolver conhecimento, mas onde esse indivíduo, vinculado ao mundo que o cerca, possa desenvolver um conhecimento crítico e interpretativo sobre seu próprio mundo.

Então nas palavras de Chagas (2003: 97):

Essas noções simples favorecem o entendimento de que a preservação de um aglomerado de bens (tangíveis ou intangíveis) não constitui por si só um patrimônio. É preciso que tanto o remetente quanto o destinatário dessa prática social reconheçam e agreguem valores a esse mesmo aglomerado de bens, que poderá ser transmitido de uma geração para outra (perspectiva diacrônica), como também poderá ser partilhado numa mesma geração (perspectiva sincrônica).

Diante da realidade de um país multicultural, a educação patrimonial precisa estar presente em todas as instancias do ensino e da produção de conhecimento e deveria ser considerada um objeto relevante de reflexão por aqueles que pensam e articulam a educação brasileira.

\subsection{Oficinas e cursos para comunidade, professores e alunos das escolas da região.}

Numa perspectiva abrangente, cabe ao LEPAN / FURG realizar um ciclo completo de atividades que englobe os fazeres e saberes inerentes à vida da comunidade. Dessa forma, a importância que ganha as oficinas abertas ao público em geral, como uma forma de envolvêlos nas pesquisas, enfatizando o papel principal que estas pessoas possuem na formação do conhecimento sobre a sua comunidade e a sua história. Este é sim o lado mais visível da interação com a comunidade, que não poderá se cumprir sem a plena congregação entre 
universidade e comunidade local, que envolve a inserção dos pesquisadores na vida dessas pessoas.

A experiência das pesquisas em curso sobre os sítios arqueológicos da região tem se mostrado importante como experiência mobilizadora da comunidade para a reflexão sobre as questões referentes ao passado e a história do lugar que habitam, estabelecendo um diálogo com o presente e com a universidade que passa agora a freqüentar a comunidade constantemente.

Assim, essas oficinas serão elaboradas pelo grupo de pesquisadores, de acordo com os interesses locais, já que serão fruto de pesquisas etnográficas junto aos moradores, e suas atividades cotidianas. Deverão se dar no âmbito das escolas, já que os professores serão os maiores parceiros nessas atividades, congregando alunos e pais de alunos, mas também se farão em locais mais abrangentes. Estas oficinas terão como linha mestra observação do ambiente no entorno do lugar onde moram, e onde se encontram vestígios arqueológicos e de outros elementos construtores da identidade local, como casas, paisagens, trilhas, etc. E se desenvolverá através de atividades práticas, como fotografias, desenhos, colagens, construções de histórias, vídeos, e outras atividades, que irão sendo permeadas por explicações conceituais.

Mas, ainda dentro da proposta das oficinas, serão ministradas visitas guiadas, oficinas lúdicas, audição e visualização de músicas e vídeos, com palestras e discussões que suscitem a curiosidade e a construção do conhecimento pelos expectadores e participantes dessas atividades.

E por fim, propomos a realização de um evento acadêmico no município, buscando aproximar estes universos diferentes num mesmo ambiente. Esse evento se daria como um seminário temático, onde pesquisadores da universidade e locais interagiriam dentro de um diálogo amplo. Seriam dois dias de encontro, com temas e discussões sobre as pesquisas na região e sobre as memórias e histórias locais. Representantes da universidade e dos poderes públicos também participariam deste encontro, para poderem dialogar com a comunidade.

Este evento seria a proposta final do projeto de educação patrimonial e arqueologia colaborativa no âmbito prático.

3.6. Montagem de um Centro de Memória, através de convênios e pesquisa. 
Como o trabalho de pesquisa arqueológica visa sempre a retirada de materiais de um lugar, e, portanto o deslocamento desse patrimônio para fora da comunidade a que ele pertence, e este projeto propõe o envolvimento da comunidade nas práticas de pesquisa e uma construção de identidade local e regional que valorize este patrimônio histórico, sendo ele construtor de uma memória coletiva, se faz mister pensar numa maneira de alocar o material arqueológico e todos os elementos produzidos durante esta pesquisa de campo, através das oficinas, dos cursos, das visitas e demais atividades junto a comunidade, num lugar dentro do município, que possa desta forma ser um elemento de agregação da comunidade com seu acervo patrimonial.

Esta proposta do programa requer um investimento muito maior do que até agora elencado, por isso pretendemos durante a execução deste buscar convênios com instituições de pesquisa e desenvolvimento sustentável, para elaborar uma proposta de criação de um centro de memórias, que poderá ser, além de um depositário de todo um legado histórico cultural da comunidade, gerador de empregos e pólo turístico.

\section{Bibliografia Consultada:}

BOADO, Felipe Criado. Hacia una arqueologia de los paisajes imaginarios. La Plata: UNLP, Departamento de Posgrado, 1996.

BOUILHET, Henry \& GIRAUDY, Daniele. O museu e a vida. Belo Horizonte: UFMG, Fundação Pró - Memória, 1990.

BOURQUE, Bruce J. Diversity and complexity in prehistoric marine societies. A gulf of Maine perspective. New York: Plenum, 1995.

CABRAL, Mariana P. Sobre coisas, lugares e pessoas: uma prática interpretativa na arqueologia de caçadores coletores do sul do Brasil. Dissertação de mestrado. Porto Alegre: PPGH/PUCRS, 2005.

CHAGAS, Mario \& ABREU, Regina. Memória e Patrimônio: ensaios contemporâneos. Rio de Janeiro: DP\&A, 2003.

DE CERTEAU, Michel. A escrita da História. Rio de Janeiro: Forense Universitária, 2002.

N

$N$

FEVRE, Lucien. Combates pela História. Lisboa: Editorial Presença, 1996. 
FREIRE, Paulo \& SHOR, Ira. Medo e ousadia: o cotidiano do professor. Rio de Janeiro: Paz e Terra, 1987.

GARLET, Ivori José. Mobilidade Mbyá: História e significação. Dissertação de mestrado. Porto Alegre: PPGH/PUCRS, 1997.

HELFER, Nadir Emma \& LENSKIJ, Tatiana. A memória e o ensino de historia. Santa Cruz do Sul: EDUNISC / ANPUH/RS, 2000.

KERN, Arno A. As origens pré - históricas do povoamento de Torres. In: VIII Reunião Cientifica da SAB. Porto Alegre: SAB, 1995.

KERN, Arno A. A cultura material, a história e a arqueologia. In: Anais da $\mathbf{X}$ Reunião da Sociedade Brasileira de Pesquisa Histórica (SBPH), Curitiba, 1991.

KERN, Arno A. Arqueologia Pré - histórica do Rio Grande do Sul. Porto Alegre: Mercado Aberto, 1991.

KERN, Arno. Pescadores coletores pré - históricos do litoral norte do Rio Grande do Sul. In: Revista de Arqueologia. Documento 03. São Leopoldo: IAP/UNISINOS, 1989.

KERN, Arno A. Paleo - paisagens e povoamento pré - histórico do Rio Grande do Sul. In: Estudo Ibero - Americanos. Porto Alegre: PPGH / PUCRS, 1982.

LADEIRA, Maria Inês. (org) Terras Guarani no Litoral: as matas que foram reveladas aos nossos antigos avós. Ka'agüy oreramói kuéry ojou rive vaekue y. São Paulo: CTI (Centro de trabalho indigenista), 2004.

ORTHON, Clive \& HODDER, lan. Análisis espacial en arqueologia. Barcelona: Editorial Critica, 1990.

ROGGE, Jairo Henrique. Assentamentos litorâneos da Tradição Tupi - Guarani: Projeto Quintão. In: Revista do CEPA. Santa Cruz do Sul: CEPA/UNISC, vol. 23, no 29, 1999.

RUSCHEL, Ruy Ruben. Sítios arqueológicos do Rio Grande do Sul. Porto Alegre: EST, 1966.

Prefeitura Municipal de Viamão. Inventário Participativo de Viamão. Viamão: SMCET / UFRGS, 1999.

$\infty$

ก

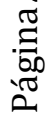

SERRANO, Antonio. Arqueologia Brasileira: subsídios para a arqueologia do Brasil meridional. In: Revista do Arquivo do Departamento de Cultura. São Paulo: ADC, 1937. 
SILVA, Tomaz Tadeu da. Documentos de identidade: uma introdução às teorias do currículo. Belo Horizonte: Autêntica, 2000.

SUGUIO, Kenitiro \& MARTIN, Louis et alii. Flutuações do nível relativo do mar durante o quaternário superior ao longo do litoral brasileiro e suas implicações a sedimentação costeira. In: Revista Brasileira de Geociências. 15 (4), 1985.

SUGUIO, Kenitiro \& MARTIN, Louis et alii. Paleoshorelines and the sambaquis of Brazil. In: Paleoshorelines and prehistory: an investigation of method. Ann Arbor, CRC Press: L L. Johnson ed., 1991.

SUGUIO, Kenitiro. Relationship between shell - middens and Neolithic paleoshorelines whit examples from Brazil and Japan. In: Revista do Museu de Arqueologia e Etnologia. São Paulo: MAE / USP, 1993.

ZIMMER, Jürgen. Pedagogia da Libertação: ensino na Nicarágua. Porto Alegre: FEPLAN, 1987. 